\title{
Alelopatia de palhadas de coberturas de inverno sobre o crescimento inicial de milho
}

\section{Allelopathy of winter cover straws on the initial maize growth}

\author{
Ariane Spiassi²; Andréa Maria Teixeira Fortes ${ }^{1 *}$; Dércio Ceri Pereira ${ }^{2}$; Jaqueline \\ Senem$^{2}$; Dayana Tomazoni ${ }^{2}$
}

\begin{abstract}
Resumo
Nas lavouras agrícolas é comum o cultivo da cultura principal sobre os restos de palha da colheita do cultivo anterior em decorrência do sistema de plantio direto. A palhada remanescente no solo pode exercer influência positiva ou negativa sobre a cultura principal pela liberação de compostos orgânicos que exercem alelopatia sobre as plantas da cultura subsequente. Este experimento constou da mistura e homogeneização das palhas de nabo (Brassica rapa L.), aveia (Avena sativa L.), crambe (Crambe abyssinica Hochst. ex R. E. Fries), cartamo (Carthamus tinctorius L.) e canola (Brassica napus L.var) no solo, que foi colocado em bandejas plásticas onde semeou-se o milho. O delineamento experimental foi inteiramente casualizados com seis tratamentos e três repetições. As características analizadas foram: emergência, índice de velocidade de emergência, comprimento de parte aérea, comprimento de raiz, massa seca de raiz, massa seca de parte aérea. As coberturas vegetais canola e cártamo apresentaram efeito positivo, já crambe, nabo e aveia tiveram efeito negativo sobre o crescimento inicial de plântulas de milho, não sendo indicadas para cobertura vegetal para semeadura do milho.
\end{abstract}

Palavras-chave: Alelopatia. Crambe abyssinica. Carthamus tinctorius. Zea mays. Cobertura vegetal.

\begin{abstract}
In agricultural crops is common planting the main crop on the remains of straw harvesting the crop earlier due to no-tillage system. The straw remaining in the soil can exert positive or negative influence on the main crop through the release of organic compounds that carry allelopathy on plants of the subsequent growing. This experiment consisted of mixing and blending of different types of turnip (Brassica rapa L.), oats (Avena sativa L.), crambe (Crambe abyssinica Hochst. Ex RE Fries), Safflower (Carthamus tinctorius L.) and rapeseed (Brassica napus L . var) in soil and placed in plastic trays where they planted the seeds of maize. The experimental design was completely randomized design with six treatments and three repetições. As ratings were: emergence, rate of emergence, shoot length, root length, root dry weight, dry weight of shoots. The cover crops canola and safflower showed a positive effect, as crambe, turnips and oats had a negative effect on initial growth of maize seedlings, are not suitable for cover crop to maize sowing.
\end{abstract}

Key words: Allelopathy. Crambe abyssinica. Carthamus tinctorius. Zea mays. Plant cover.

1 Bióloga, Dr. Docente do Curso de pós-graduação em Engenharia Agrícola da Universidade Estadual do Oeste do Paraná, UNIOESTE, Campus de Cascavel, Rua Universitária, n 2069, Bairro Jardim Universitário, Cascavel/PR. CEP 85819-110. E-mail: andrea.fortes@unioeste.br

2 Mestrando em Engenharia Agrícola. UNIOESTE, Campus de Cascavel, Rua Universitária, nº 2069, Bairro Jardim Universitário, Cascavel/PR. CEP 85819-110. E-mail: arispiassi@hotmail.com; dercioceri@gmail.com; jaquivs@hotmail.com; day_tom@ yahoo.com.br

* Autor para correspondência 
Nas lavouras agrícolas é comum o cultivo da cultura principal sobre os restos de palha da colheita do cultivo anterior em decorrência do sistema de plantio direto. Essa palhada no solo pode apresentar influência sobre a cultura principal por meio da liberação de compostos orgânicos que podem exercer alelopatia sobre as plantas. De acordo com Rice (1984) alelopatia é qualquer efeito direto ou indireto, benéfico ou prejudicial de uma espécie doadora à uma espécie receptora, podendo ser de uma planta ou de um microorganismo sobre outra planta, mediante produção de compostos químicos resultantes do metabolismo secundário que são liberados no meio.

A alelopatia é conhecida como um importante mecanismo ecológico que influencia a dominância vegetal, a sucessão, formação de comunidades vegetais e de vegetação de clímax, bem como a produtividade e manejo de culturas (MIRÓ; FERREIRA; ÁQUILA, 1997). Em experimento desenvolvido por Souza et al. (2006) o crescimento das plantas de milho, arroz, trigo, soja, feijão, algodão e braquiária foram reduzidos pela incorporação ao solo de 3,0\% (p/p) de matéria seca de B. decumbens; das sete culturas testadas, a própria B. decumbens apresentou maior sensibilidade aos efeitos de sua matéria seca.

O uso de plantas de cobertura é uma prática comum dos agricultores na entressafra, pois evita a emergência de plantas invasoras pela liberação de compostos orgânicos, proteção do solo evitando erosão, mantém a umidade, fornece nutrientes, entre outros benefícios. As plantas de cobertura do solo no inverno, em cultivos solteiros proporcionam vantagens e desvantagens para o cultivo do milho em sucessão e para o plantio direto, dificultando a indicação de uma espécie que agrupa apenas características desejáveis (SILVA et al., 2007).

Desta forma, o objetivo deste trabalho foi avaliar os efeitos alelopáticos de palhas de nabo (Brassica rapa L.), aveia (Avena sativa L.), crambe (Crambe abyssinica Hochst. ex R. E. Fries), cartamo (Carthamus tinctorius L.) e canola (Brassica napus L.var) utilizadas como cobertura do solo durante o inverno sobre o crescimento inicial de milho.

O experimento foi conduzido em estufa modelo arco na Universidade Estadual do Oeste do Paraná - UNIOESTE de Cascavel - PR, localizada a $02^{\circ}$ 46' 483'S de latitude, $72^{\circ} 39^{\prime} 117^{\prime}$ 'W de longitude e, com altitude média de $700 \mathrm{~m}$.

O substrato utilizado foi constituído de solo coletado da camada arável, classificado como Latossolo Roxo Distrófico típico (EMBRAPA, 2006), ocorrente na região. O solo depois de coletado foi seco à sombra e passado em peneira com malha de $6 \mathrm{~mm}$, sendo enviado para análise de nutrientes. As características químicas do solo são apresentadas na (Tabela 1).

Tabela 1. Resultados da análise química do solo utilizado como substrato - Cascavel, 2009.

\begin{tabular}{lcccccccc}
\hline Prof (cm) & $\mathbf{p H ~ C a C l}$ & $\mathbf{C a}$ & $\mathbf{M g}$ & $\mathbf{K}$ & $\mathbf{C T C}$ & $\mathbf{C g ~ d m}^{-3}$ & $\mathbf{P ~} \mathbf{~ m g ~ d m}^{-3}$ & $\mathbf{V \%}$ \\
\hline $0-10$ & 5,10 & 5,39 & 1,76 & 0,57 & 13,07 & 26,88 & 10,90 & 59,07 \\
\hline
\end{tabular}

Cooperativa Central de Pesquisa Agrícola (COODETEC) - Cascavel, 2009.

O delineamento experimental foi inteiramente casualizado com seis tratamentos e três repetições. $\mathrm{O}$ experimento constou de mistura e homogeneização das palhas de nabo (Brassica rapa L.), aveia (Avena sativa), crambe (Crambe abysinica), cartamo
(Carthamus tinctorius) e canola (Brassica napus L.var) no solo, o qual foi colocado em bandejas de plástico $(27 \times 9 \times 16,5 \mathrm{~cm})$ com capacidade para 3,5 L, contendo $2 \mathrm{~kg}$ do substrato. Para evitar eventuais perdas de água por percolação durante o 
processo de irrigação, foram usadas bandejas com base sem drenos. Os tratamentos foram: $\mathrm{T}_{0}$ (sem palha); $\mathrm{T}_{1}$ (palha de nabo); $\mathrm{T}_{2}$ (palha de aveia); $\mathrm{T}_{3}$ (palha de crambe); $\mathrm{T}_{4}$ (palha de cartamo); $\mathrm{T}_{5}$ (palha de canola).

As plantas foram coletadas durante o inverno (2008), em área agrícola no município de CascavelPR. A parte aérea foi seca em estufa de circulação forçada de ar a $65{ }^{\circ} \mathrm{C}$ por $72 \mathrm{~h}$, sendo, a seguir, triturada em moinho do tipo faca e acondicionada em sacos plásticos.

A massa seca das plantas foi adicionada e homogeneizada manualmente no substrato na proporção de $3 \%$ peso/peso (p/p), segundo a metodologia de Souza et al. (2006). A instalação do experimento foi efetuada pela semeadura de milho, com 50 sementes por bandeja. A irrigação foi efetuada diariamente de forma a restabelecer a capacidade de campo do substrato, controlando-se a necessidade de irrigação de acordo com a evaporação da água seguindo o método do tanque classe A (DOORENBOS; PRUITT, 1977). Procedeu-se à mudança na posição das bandejas dentro da estufa a cada dois dias.

O experimento foi conduzido durante sete dias procedendo a contagem do número de plântulas no primeiro dia da emergência (ruptura e surgimento das plântulas na superfície do solo). O índice de velocidade de emergência (IVE) foi quantificado, utilizando-se o método de Maguire (1962), de acordo com a fórmula IVE $=\Sigma(\mathrm{Pi} / \mathrm{Di})$, em que: IVE = índice de velocidade de emergência; $\mathrm{Pi}=$ número de plântulas emergidas no i-ésimo dia de contagem; Di = número de dias que as plântulas levaram para emergir no i-ésimo dia de contagem.

Ao final do experimento ( $\left.7^{\circ} \mathrm{dia}\right)$, quando a emergência estava estabilizada, as bandejas foram mergulhadas em água, lavando as raízes para retirada do substrato. Procedeu-se a separação, por meio de corte da parte aérea e das raízes para determinar o comprimento da parte aérea (CPA) e da raiz (CR). Posteriormente, a parte aérea e as raízes separadas foram secas em estufa de circulação forçada de ar a $65{ }^{\circ} \mathrm{C}$ por $72 \mathrm{~h}$ até obtenção de peso constante, e sua matéria seca foi determinada em balança de precisão.

Os resultados foram submetidos à análise de variância pelo teste $\mathrm{F}$ e as médias comparadas pelo teste $\mathrm{t}$ (LSD) a 5\% de probabilidade com uso do programa Sisvar versão 4.3 (FERREIRA, 2000).

Houve diferenças significativas entre as diferentes palhas avaliadas sobre o desenvolvimento inicial de plantas de milho, como pode ser observado na (Tabela 2). A emergência das plântulas de milho foi atrasada pelo uso das palhas quando comparado com o solo sem palhas, indicando que a massa seca adicionada ao solo teve influência na emergência das plântulas. Na avaliação do índice de velocidade de emergência (IVE), verificou-se menor quantidade de plântulas com a incorporação de palha de nabo, aveia e crambe. Isso pode estar relacionado ao excesso de palha, sendo suficiente para impedir a velocidade de emergência, apesar todos os tratamentos terem recebido as mesmas quantidades de palhada. Ramos et al. (2009) detectaram menor índice de velocidade de emergência do girassol conforme a elevação da quantidade de palha de cana-de-açúcar estimandose o menor IVE com 13,5 $\mathrm{t} \mathrm{ha}^{-1}$.

A palha de cártamo proporcionou efeito positivo sobre as plântulas de milho, as quais tiveram maior crescimento, uma vez que o comprimento inicial e a massa seca da parte aérea foram estimulados. Como exemplo, Rice (1984) observou que a alfafa picada adicionada ao solo estimulou o crescimento de fumo, pepino e alface. 
Tabela 2. Valores médios de emergência (E), índice de velocidade de emergência (IVE), comprimento da parte aérea (CPA), comprimento de raiz (CR), massa seca da parte aérea (MSPA), massa seca de raiz (MSR) na cultura do milho em função das diferentes palhas. UNIOESTE, Cascavel, 2009.

\begin{tabular}{lclllrr}
\hline Tratamentos & $\begin{array}{c}\text { E } \\
\mathbf{1}^{\circ} \text { dia }\end{array}$ & IVE & CPA & CR & MSPA & MSR \\
\hline Sem palha & $11,667 \mathrm{a}$ & $38,600 \mathrm{a}$ & $10,520 \mathrm{bc}$ & $17,260 \mathrm{a}$ & $2,118 \mathrm{bc}$ & $9,997 \mathrm{ab}$ \\
Palha de nabo & $1,000 \mathrm{c}$ & $34,533 \mathrm{c}$ & $10,907 \mathrm{~b}$ & $15,107 \mathrm{~b}$ & $2,223 \mathrm{ab}$ & $9,989 \mathrm{ab}$ \\
Palha de aveia & $0,000 \mathrm{c}$ & $34,633 \mathrm{bc}$ & $10,840 \mathrm{~b}$ & $17,140 \mathrm{a}$ & $2,071 \mathrm{~cd}$ & $10,104 \mathrm{ab}$ \\
Palha de crambe & $0,000 \mathrm{c}$ & $33,600 \mathrm{c}$ & $9,553 \mathrm{c}$ & $8,907 \mathrm{c}$ & $1,964 \mathrm{~d}$ & $10,413 \mathrm{a}$ \\
Palha de cártamo & $0,000 \mathrm{c}$ & $36,067 \mathrm{abc}$ & $12,210 \mathrm{a}$ & $16,170 \mathrm{ab}$ & $2,272 \mathrm{a}$ & $9,789 \mathrm{~b}$ \\
Palha de canola & $6,667 \mathrm{~b}$ & $37,500 \mathrm{ab}$ & $11,193 \mathrm{~b}$ & $16,887 \mathrm{ab}$ & $2,257 \mathrm{ab}$ & $10,173 \mathrm{ab}$ \\
DMS & 4,574 & 2,936 & 0,989 & 1,994 & 0,148 & 0,448 \\
CV\% & 79,800 & 4,610 & 12,110 & 17,35 & 3,87 & 2,50
\end{tabular}

NOTA: letras diferentes nas colunas indicam diferença estatisticamente significativa pelo teste $\mathrm{t}$ LSD a $5 \%$ de probabilidade.

A palha de crambe propiciou redução no comprimento da parte aérea, raiz e massa seca da parte aérea das plântulas de milho no presente estudo, o que infere que o crescimento de tais plantas é sensível à referida palha. Tal fato pode estar relacionado à ação inibitória, o que caracteriza efeito alelopático negativo sobre as plântulas de milho. Estudos realizados por Prates et al. (2000) com o extrato aquoso da parte aérea da leucena mostraram que não houve efeito fitotóxico sobre a germinação e o desenvolvimento das plantas de milho (Zea mays).

As plântulas de milho originadas do tratamento com palha de crambe reduziram o crescimento radicular em 51,60\% em relação ao controle. De acordo com Ferreira e Borghetti (2004) o crescimento da plântula é mais sensível aos aleloquímicos do que a germinação, pois o modo de ação direto dos aleloquímicos atua a partir da ligação nas membranas da planta receptora (milho) ou penetra nas células, provocando interferência no metabolismo.

Houve pouco acúmulo de massa seca da parte aérea das plântulas milho com o uso da palha de crambe. Isso pode ser justificado pela quantidade de palha utilizada no solo e/ou, pela liberação de substancias da palha de crambe devido à umidade mantida durante a condução do experimento favorecendo a liberação de compostos orgânicos. Segundo Correia e Durigan (2008) os efeitos alelopáticos evolvem a liberação de compostos orgânicos que inibem a germinação e o desenvolvimento de espécies cultivadas e plantas invasoras.

Silva et al. (2007) relatam que a redução no rendimento de grãos do milho em sucessão com a aveia provavelmente seja devido à sua semeadura ser realizada um dia após o manejo. Por outro lado, no presente estudo a palha de cártamo proporcionou acréscimos de massa seca de parte aérea nas plântulas de milho, no entanto esta não diferiu daquela proporcionada pelas palhas de nabo e canola.

O tratamento com palha de canola não apresentou efeito negativo na cultura do milho, o que indica que esta pode ser utilizada como cobertura vegetal no solo antes da semeadura do milho, pois estimulou o crescimento com conseqüente aumento da massa seca de parte aérea.

Quanto à massa seca de raiz verificou-se que a palha de cártamo apresentou efeito inibitório sobre o crescimento radicular das plântulas de milho com 
porcentagem de $3 \%$ de palha, diferindo da palha de crambe a qual influenciou a massa seca de raiz positivamente dentre os tratamentos, evidenciando efeito crescimento radicular. De acordo com Souza et al. (2006), as proporções mínimas de Brachiaria decumbens de 0,5 e 1\%, com e sem Sphagnum sp., respectivamente, incorporadas ao solo, apresentaram efeito inibitório no desenvolvimento inicial de eucalipto (Eucalyptus grandis). Com isso, a altura, o teor de clorofila, a área foliar e a massa seca de folhas, caule e raiz foram às características que apresentaram maior sensibilidade aos efeitos dos tratamentos com Brachiaria decumbens incorporada ao solo nas proporções $0,5,1,0,2,0$ e $3,0 \%$ peso/peso.

As coberturas vegetais canola e cártamo apresentaram efeito positivo, já crambe, nabo e aveia tiveram efeito negativo sobre o crescimento inicial de plântulas de milho, não sendo indicadas para cobertura vegetal para semeadura do milho.

\section{Referências}

CORREIA, N. M.; DURIGAN, J. C. Culturas de cobertura e sua influência na fertilidade do solo sob sistema de plantio direto. Bioscience Journal, Uberlândia, v. 24, n. 4, p. 20-31, 2008.

DOORENBOS, J.; PRUITT, W. O. Crop water requeriments. Rome: FAO, 1977. 179 p. (Irrigation and Drainage Paper, 24).

EMPRESA BRASILEIRA DE PESQUISA AGROPECUÁRIA - EMBRAPA. Centro Nacional de Pesquisa de Solos. Sistema brasileiro de classificação de solos. 2. ed. Rio de Janeiro: Embrapa Solos, 2006. 306 p.

FERREIRA, A. G.; BORGHETTI, F. Germinação do básico ao aplicado. 2. ed. Porto Alegre: Artmed, 2004. $323 \mathrm{p}$.

FERREIRA, D. F. Manual do sistema Sisvar para análises estatísticas. Lavras: UFLA, 2000. 66 p.

MAGUIRE, J. D. Speed of germination aid in selection and evaluation for seedling emergence and vigor. Crop Science, Madison, v. 2, n. 2, p. 176-177, 1962.

MIRÓ, C. P.; FERREIRA, A. G.; ÁQUILA, M, E. A. Alelopatia de frutos de erva-mate (Ilex Paraguariensis) no desenvolvimento do milho. Pesquisa Agropecuária
Brasileira, Brasília, v. 33, n. 8, p. 1261-1270, 1998.

PRATES, H. T.; PAES, J. M. V.; PIRES, N. M.; PEREIRAFILHO, I. A.; MAGALHÃES, P. C. Efeito do extrato aquoso de leucena na germinação e no desenvolvimento do milho. Pesquisa Agropecuária Brasileira, Brasília, v. 35, n. 5, p. 909-914, 2000.

RAMOS, N. P.; NOVO, M. C. S. S.; LAGO, A. A.; UNGARO, M. R. G. Girassol: emergência e crescimento inicial de plantas sob resíduos de cana-de-açúcar. Ciência Rural, Santa Maria, v. 39, n. 1, p. 45-51, 2009.

RICE, E. L. Allelopathy. 2. ed. New York: Academic Press, 1984.

SILVA, A. A.; SILVA, P. R. F.; SUHRE, E.; ARGENTA, G.; STRIEDER, M. L.; RAMBO, L. Sistemas de coberturas de solo no inverno e seus efeitos sobre o rendimento de grãos do milho em sucessão. Ciência Rural, Santa Maria, v. 37, n. 4, p. 928-935, 2007.

SOUZA, L. S.; VELINI, E. D.; MARTINS, D.; ROSOLEM, C. A. Efeito alelopático de capim-braquiária (Brachiaria decumbens) sobre o crescimento inicial de sete espécies de plantas cultivadas. Planta Daninha, Viçosa, v. 24, n. 4, p. 657-668, 2006. 
